\title{
A formação de leitores em Salas de Leitura: diretrizes oficiais, saberes docentes e contextos sociais
}

\section{The formation of readers in school Reading Rooms: official guidelines, teacher knowledge and social context}

https://doi.org/10.34112/2317-0972a2020V38n80p13-27

EMERSON DE Pietri ${ }^{1}$

Luciene de Cassia de Santana ${ }^{2}$

ResUmO: Neste trabalho são apresentados resultados de pesquisa orientada pelo objetivo de conhecer as representações de leitura e de leitor constituídas em contextos escolares específicos para a formação de leitores. Observaram-se as relações estabelecidas entre os saberes docentes, as diretrizes oficiais de funcionamento dos espaços institucionais para a formação leitora e as características sociais e econômicas condicionantes dos contextos escolares considerados. $\mathrm{O}$ corpus de análise foi composto por planos de trabalho elaborados por professoras de Salas de Leitura de escolas da Rede Municipal de Ensino de São Paulo. A análise dos dados evidenciou que as representações de leitura e de leitor observadas nos planos de trabalho analisados se constituem heterogeneamente em função dos diferentes modos como respondem aos objetivos de formação estabelecidos pelas diretrizes oficiais, mas, principalmente, dos modos como respondem aos saberes docentes, às necessidades dos sujeitos da aprendizagem e ao contexto social e econômico em que as atividades didáticas serão desenvolvidas.

PALAVRAS-CHAVE: Formação de leitores; saberes docentes; contexto escolar.

ABSTRACT: In this work, research findings about the constitution of reading representations in school context are presented. The investigation was developed in three schools

1. Faculdade de Educação da Universidade de São Paulo, São Paulo, SP, Brasil.

2. Secretaria de Estado da Educação de São Paulo - SEDUC, São Paulo, SP, Brasil. 
A formação de leitores em Salas de Leitura: diretrizes oficiais, saberes...

located in contexts characterized by economic and social vulnerability. Relationships established among teacher knowledge, the official guidelines for the teaching of reading, and the schools' social and economic conditions were observed. The corpus of analysis was composed of teachers' work plans for the formation of readers in public schools' Reading Rooms in the city of São Paulo. The analysis of the data showed that the reading representations characterized in the observed work plans do not correspond to those established by the institutional guidelines, but mainly to the needs of the learners, to teachers' knowledge and to the school social and economic context.

KEYWORDS: Formation of readers. Teacher knowledge. School context

\section{INTRODUÇÃO}

No presente trabalho, busca-se conhecer que efeitos os fatores relacionados ao contexto escolar e aos sujeitos que dele participam, principalmente o professor com suas concepções pedagógicas e os saberes de sua especialidade, produzem sobre a constituição de propostas de ensino de leitura e de formação de leitores.

Apresentam-se resultados de pesquisa desenvolvida com o objetivo de conhecer como se constituem as representações de leitura e de leitor em contextos escolares específicos de formação de leitores. Para responder a esse objetivo, observaram-se as relações entre saberes docentes, diretrizes oficiais de funcionamento dos espaços institucionais para a formação de leitores e as características sociais e econômicas condicionantes dos contextos escolares considerados.

O corpus de análise foi composto de planos de trabalho elaborados por professoras da Rede Municipal de Ensino da cidade de São Paulo para sua atuação como Professores Orientadores de Sala de Leitura ${ }^{3}$. As escolas observadas se caracterizam por estarem localizadas em territórios socialmente vulneráveis. A seleção de escolas com essas características se realizou devido a se apresentarem mais perceptíveis, nessas condições, os efeitos dos fatores sociais e econômicos sobre o contexto de ensino e de aprendizagem.

Nos processos metodológicos de caracterização dos contextos escolares e de produção e categorização dos dados, consideraram-se os efeitos dos discursos e das práticas de sujeitos e instituições sobre a produção dos planos de trabalho analisados.

3. Docentes dos diferentes componentes curriculares da escola básica podem atuar como professores nesses espaços, de acordo com critérios determinados, os quais serão apresentados mais adiante no presente trabalho. 
O CONTEXTO DA PESQUisa

O "Programa Sala de Leitura”, da Rede Municipal de Ensino de São Paulo (RMESP), surgiu em 1972 e, no decorrer de suas quatro décadas de existência, passou por diversas mudanças, no que se refere tanto à estrutura física das Salas quanto ao modo de seu funcionamento (FIRMINO, 2015; LEITE, 2009; POLIDO, 2012). Atualmente, as atividades das Salas de Leitura fazem parte da grade curricular de todos os alunos do Ensino Fundamental I e II. Cada turma tem, semanalmente, uma aula regular de 45 minutos, com o apoio do Professor Orientador da Sala de Leitura (POSL), cujas atuais funções são regulamentadas pela Portaria n. ${ }^{0} 7655$, de 17 de dezembro de 2015.

Quanto aos seus objetivos, definidos por diretrizes oficiais, as Salas de Leitura devem contribuir para a aprendizagem de diferentes gêneros textuais, promover $o$ acesso à produção literária clássica e contemporânea, dar visibilidade às literaturas não hegemônicas, à literatura marginal periférica, à literatura de mulheres, negros e Lésbicas, Gays, Bissexuais, Travestis, Transexuais e Transgêneros - LBGT. As diretrizes de funcionamento das Salas de Leitura informam também que estas devem estabelecer dialogicidade com o currículo, numa perspectiva emancipatória, a partir do diálogo com o trabalho pedagógico e a leitura, de modo a promover processos de compreensão mais abrangentes da realidade.

Para candidatar-se a POSL, o docente interessado deve submeter seu plano de trabalho à avaliação do Conselho de Escola e da supervisão escolar, que deliberam quanto à propriedade ou não de seu desenvolvimento. Desse modo, ainda que apresentem possibilidades formativas diversificadas, quando comparadas às tradicionalmente definidas no currículo escolar comum, as Salas de Leitura se constituem como contextos rigidamente controlados na estrutura institucional.

Como apontam os estudos de Carmo (2012), Mendes (2006) e Piovesan (1999), diretrizes institucionais específicas estabelecem inclusive quais atividades de leitura devem ser desenvolvidas nas Salas de Leitura, como a leitura dirigida, o uso de fichas, a dramatização, a leitura livre, a hora do conto, a realização de debates, e definem também as regras que orientam o empréstimo de livros. Mendes (2006) e Piovesan (1999) observaram que algumas das atividades previstas para a Sala de Leitura poderiam promover um trabalho mecânico, de decodificação, ocultando dos leitores em formação a multiplicidade de sentidos que podem se constituir nos processos de leitura. 
O trabalho na Sala de Leitura da Rede Municipal de Educação de São Paulo é orientado por material de apoio denominado "Leitura ao Pé da Letra". Prevalecem, nesse material, valores e representações de leitura associados ao prazer, ao gosto, à imaginação, ao desejo, à conquista da cidadania e de autonomia, mediante o ensino de diversos gêneros textuais, enfatizando-se a primazia do livro em relação a outros suportes que circulam socialmente, bem como a legitimidade da "boa literatura" (SÃO PAULO [município], 2012, p. 12).

As diretrizes institucionais para as Salas de Leitura privilegiam a perspectiva do prazer, da imaginação, da fantasia, com foco na leitura literária, que, como um direito inalienável do ser humano, possibilitaria a emancipação individual, ao permitir conhecer várias leituras da realidade, representadas em diferentes gêneros, linguagens e contextos sociais, culturais e históricos.

A leitura parece ser representada, assim, como atividade desenvolvida numa dimensão individual, privada, como um processo intimista. Caracteriza essa perspectiva a recorrência, no documento, de palavras-chave como gosto, interesse, curiosidade, prazer, fruição, imaginação, fantasia, sonho. $\mathrm{O}$ ato de ler parece ser concebido como de escolha livre do sujeito, desprendido de outros condicionamentos, como os sociais ou os culturais, por exemplo: "à Sala de Leitura cabe o papel de promover o prazer e a fruição da leitura da literatura, possibilitando aos alunos escolher o que querem ler" (SÃO PAULO [município], 2012, p.67).

Porém, é preciso observar que, para sujeitos que vivem em territórios vulneráveis, caracterizados pela precarização da oferta de serviços públicos de saúde, habitação, educação, cultura e lazer, as práticas de leitura respondem também, necessariamente, e de modo ainda mais incisivo, a questões sociais, políticas e econômicas, o que produz efeitos sobre a constituição de representações de leitura e de formação de leitores nesses contextos escolares específicos.

\section{FundamentaÇão teórico-Metodológica e CONSTITUIÇão Do CORPUS}

Para Chartier (1990), representação refere-se ao modo pelo qual, em diferentes lugares e momentos, uma determinada realidade é construída, pensada e dada a conhecer por diferentes grupos sociais. A representação consiste, assim, em seleções, exclusões e classificações para a constituição de compreensões próprias de um tempo ou de um espaço. A noção de representação, de certa maneira, definiria, 
assim, a forma como as pessoas organizam a realidade em suas mentes, como são definidos os comportamentos e as práticas sociais (CHARTIER, 1990, p. 17).

Chartier (2003, p. 153) lembra que "as práticas culturais são sempre objetos de lutas sociais que têm por risco sua classificação, hierarquização, sua consagração (ou ao contrário, sua desqualificação)”. Para evitar que a produção de conhecimentos sobre as práticas de leitura reproduza esses processos excludentes, é preciso ponderar que os objetos de estudo menos "distintos" merecem a mesma atenção que os considerados "mais distintos" (CHARTIER, 2007). Portanto, o que está em jogo não é classificar as representações de ensino e de leitor como "boas" ou "más", "legítimas" ou "ilegítimas", mas, principalmente, entender o "processo pelo qual um texto, uma fórmula, uma norma fazem sentido para os que deles se apoderam ou os recebem" (CHARTIER, 1991, p. 181).

A produção e a análise dos dados nesta pesquisa se fundamentaram no princípio de que as práticas sociais de produção de sentidos se constituem em processos de tensionamento entre representações concorrentes, diferenciadas em seus condicionamentos sociais (CHARTIER, 1999, p. 15). São observadas as relações de força entre as representações impostas por aqueles que "detêm o poder de classificar e de nomear e a definição, de aceitação ou de resistência, que cada comunidade produz de si mesma" (CHARTIER, 1991, p. 183), o que, na presente pesquisa, refere-se às determinações institucionais para a formação escolar de leitores, aos saberes dos professores que se responsabilizam pela educação para a leitura, e aos contextos em que esses processos formativos se realizam.

Assim, observam-se os processos de tensionamento que se operam, em contextos específicos, nesse "amálgama, mais ou menos coerente, de saberes oriundos da formação profissional e de saberes disciplinares, curriculares e experienciais" (TARDIF, 2004, p. 36), que constitui os saberes docentes. No contexto em análise no presente estudo, observam-se as tensões entre representações de leitura e de leitor estabelecidas pelas instâncias oficiais responsáveis por definir os objetivos da formação de leitores nas Salas de Leitura e as representações construídas pelas docentes autoras dos planos de trabalho que compõem o corpus da pesquisa, em função de suas relações com sua formação profissional, os saberes disciplinares e curriculares, os sujeitos da aprendizagem; e com o contexto cultural, social e econômico em que estão localizadas as escolas onde desenvolvem suas práticas pedagógicas.

Fundamentando-se nas considerações de Foucault (2013) sobre o fato de que a produção dos enunciados se realiza condicionada por relações regulares com 
A formação de leitores em Salas de Leitura: diretrizes oficiais, saberes...

outros enunciados, com que concorrem ou que os precedem, e que "todo sistema de educação é uma maneira política de manter ou de modificar a apropriação dos discursos, com os saberes e os poderes que eles trazem consigo" (FOUCAULT, 1996, p. 44), o material de análise foi tratado metodologicamente de modo a observar-se como os enunciados constituintes dos planos de trabalho analisados respondiam a enunciados próprios aos discursos normativos de base institucional, com as injunções oficiais sobre o que se deve fazer numa Sala de Leitura, mas também a enunciados associados aos discursos acadêmicos e profissionais a que se filiavam as professoras das Salas de Leitura, autoras dos planos de trabalho.

Uma vez que os dados de análise se constituem em condições de vulnerabilidade social, pressupôs-se, também, que a apropriação e a distribuição social dos bens simbólicos (BOURDIEU, 2007) são condicionadas por fatores socioeconômicos, e, portanto, pelas relações de poder que se constituem historicamente. Nesse sentido, para o tratamento metodológico do material de análise, observaram-se também os modos como os enunciados constituintes dos planos de trabalho que compõem o corpus da pesquisa respondem às condições sociais e econômicas dos contextos em que as atividades didáticas planejadas seriam desenvolvidas.

De quinze escolas com que se manteve contato para a obtenção de documentos para compor o corpus de análise, localizadas na região norte da cidade de São Paulo (região do Jaçanã-Tremembé), foram selecionadas quatro para o estudo, dentre as quais três forneceram material suficiente para análise. A seleção se fez de modo a considerar o nível e o grau de vulnerabilidade social da comunidade atendida, observando-se não apenas as unidades mais segregadas territorialmente, onde se faz mais difícil o acesso a serviços de saúde, de transporte, ou de equipamentos culturais, mas também aquelas que, embora menos periféricas, atendessem a alunos provenientes de bairros localizados em territórios de maior vulnerabilidade. As escolas observadas serão referidas como EMEF (Escolas Municipais de Ensino Fundamental), seguidas de letras que as localizam no processo metodológico $(A, B$ e $C)$.

$\mathrm{O}$ contato com as unidades escolares ocorreu mediante telefonemas, e-mails e visitas presenciais. Os documentos analisados foram disponibilizados via e-mail pelas docentes sujeitos da pesquisa. Para a caracterização do contexto institucional das Salas de Leitura foram observados ainda os textos de legislação (Decretos e Portarias) que regulamentam esses espaços de ensino, além do material pedagógico específico de apoio ao trabalho docente. 
Os Projetos Político-Pedagógicos das escolas, também disponibilizados à pesquisadora via e-mail, cumpriram papel fundamental no que diz respeito à possibilidade de caracterização da realidade social constitutiva dessas instituições e dos territórios em que se localizam, com as dificuldades enfrentadas pelas unidades escolares diante das várias problemáticas que se apresentam ao processo de ensino e aprendizagem da leitura.

Em relação ao segmento educacional, a pesquisa tem como escopo os anos finais do Ensino Fundamental II. A escolha desse segmento se justifica pelo fato de ele representar um momento do processo de escolarização básica, em que temáticas de maior complexidade podem ser apresentadas aos alunos.

\section{Análise dos Planos de Trabalho}

Como mencionado, compõem o corpus de análise três planos de trabalho, destinados às Salas de Leitura das Escolas Municipais de Ensino Fundamental. Eles assim se intitulam: "Cartografia" (EMEF A); "Drogas e Sexualidade" (EMEF B); e "Leituras e Releituras - do Livro à Mídia" (EMEF C). Sua análise foi realizada em associação com a caracterização dos contextos em que está localizada cada uma das escolas estudadas. Foram observadas, em cada plano de trabalho, as características do território em que se encontra a escola; as propostas de atividades a serem realizadas na Sala de Leitura; as marcas discursivas que indicam, no plano de trabalho, a presença dos saberes próprios à área de especialidade da professora autora do plano; a(s) diretriz(es) estabelecida(s) na legislação para o funcionamento escolar, a que se recorre para justificar a procedência institucional da proposta.

A ordem de observação das escolas e de suas respectivas Salas de Leitura está organizada, na seção de análise, partindo daquela em que o plano de trabalho responde mais de perto às necessidades do contexto de ensino, para aquela em que se responde mais proximamente às diretrizes institucionais de funcionamento das Salas de Leitura. Esta ordenação busca responder à hipótese que orienta o processo analítico de que a área de formação específica do professor e os saberes acadêmicos próprios dessa área favorecem modos distintos de relacionamento com as diretrizes oficiais das Salas de Leitura, conforme aqueles se aproximem mais ou menos dos objetivos principais definidos institucionalmente para a formação leitora — neste caso, a formação do leitor literário. 
A formação de leitores em Salas de Leitura: diretrizes oficiais, saberes...

O plano de trabalho em Sala de Leitura na EMEF a

O território em que está situada a EMEF A caracteriza-se pela precarização da infraestrutura, pelo saneamento básico deficitário, por ocupações habitacionais desordenadas e pelo impacto das condições climáticas no território, sobretudo em relação a enchentes. A própria unidade escolar sofre esses impactos, com a perda de bens duráveis e não duráveis, o que acarreta, por vezes, a interdição da Sala de Leitura e a perda de seu acervo: no ano de 2016, a SL ficou fechada por 20 dias, e cerca de 300 livros foram atingidos pelas águas.

Nesse contexto, o plano de trabalho para atuação na Sala de Leitura, apresentado pela POSL, docente da área de Geografia, fundamenta-se em conhecimentos da Cartografia. Propõe-se, no plano de trabalho, que os alunos realizem atividades de análise de imagens de satélite das ruas do entorno da escola; em grupos, observem e discutam sobre o que estão visualizando, como espaços de moradia, ruas de comércio, terrenos baldios etc. Numa segunda etapa, a partir da análise dos documentos e das discussões sobre os impactos das enchentes na região, os alunos são orientados a pensar sobre possibilidades de enfrentamento desse problema e a justificar por que determinadas áreas foram representadas nos mapas e outras não.

A área de formação específica da POSL fundamenta a elaboração do plano de trabalho e evidencia as representações de leitura e de ensino da leitura que orientam suas propostas pedagógicas, o que se pode observar na presença de: a) terminologia específica quanto ao processo de alfabetização cartográfica, no que envolve, dentre outros, mapear, espaço geográfico, domínio de símbolos, mapas, alfabetização cartográfica, imagem de satélite, ocupação do solo, conceitos de lateralidade e direção; b) propostas de atividades desenvolvidas em oficinas para construção de mapas, mediante elaboração de esboços, croquis e observação do território; c) indicação de referências bibliográficas ${ }^{4}$ específicas da área; d) seleção de material didático específico - atlas e livro didático de introdução à Cartografia.

O diálogo do plano de trabalho com as diretrizes institucionais e oficiais é observado na relação que se estabelece com o Projeto Político-Pedagógico da Escola - PPP, quando se propõe o estudo do território em que está localizada a unidade escolar, abrindo-se, assim, espaço para a proposição de atividades não necessariamente determinadas pelas diretrizes oficiais para as Salas de Leitura: "O projeto está inserido

4. Neste caso, Castrogiovanni (1998, 2000); Castrogiovanni e Costella (2006). 
no Projeto Político Pedagógico, pois estamos discutindo os territórios e ensinando os alunos a refletir, compreender e transformar os entornos e suas realidades" (SÃO PAULO [município], 2016a, p. 4). O diálogo é estabelecido também com a proposta de trabalho associado ao do Professor Orientador da Sala de Informática (POIE), de modo a "articular, em conjunto com o POIE, o planejamento e desenvolvimento do trabalho na área de integração, envolvendo os demais professores da unidade" (SÃO PAULO [município], 2015, art. $6^{\circ}$ ). Assim, estabelecendo relações com outros documentos reguladores do trabalho institucional que não apenas os relacionados à Sala de Leitura, a docente possibilita propor ações pedagógicas que excedam as previstas institucionalmente para a formação de leitores nesse espaço específico.

O plano de trabalho em Sala de Leitura na EMEF B

O contexto social da EMEF B é caracterizado pela problemática do tráfico de entorpecentes e pela gravidez precoce de adolescentes. O plano de trabalho em análise procura responder, assim, à necessidade de informar os alunos sobre temáticas que se relacionam com a realidade social da escola.

O trabalho proposto no plano parece associar uma abordagem científica a uma prática de leitura de caráter informativo: "é preciso explicar que a atração pelos entorpecentes tem um forte componente biológico. A principal razão é que o chamado sistema inibitório, a área responsável pela inibição, ainda está se desenvolvendo" (SÃO PAULO [município], 2016b, p. 01).

A proposta de ensino dialoga com a formação epistemológica da docente, graduada em Ciências Biológicas, o que se materializa no uso de linguagem e da terminologia específica para o tratamento do tema: drogas lícitas e ilícitas (conceitos gerais), dopaminas, dependência química, substâncias psicotrópicas, sistema dopaminérgico, sistema inibitório, hormônios, narcóticos, overdose, toxicidade, anfetaminas, inalantes, tolerância versus dependência. O plano de trabalho responde, assim, a problemas sociais do contexto em que se desenvolverá o ensino de leitura, mas também às especificidades da área de formação da docente que o propõe.

Os saberes acadêmicos próprios à área de formação específica da docente parecem favorecer a elaboração de propostas de ensino de leitura que respondam mais à realidade social dos estudantes a quem se dirigem que à formação para a leitura de textos literários que promovam a imaginação, o prazer, a fantasia. As diretrizes institucionais da SL, por não responderem à realidade social em que está situada 
A formação de leitores em Salas de Leitura: diretrizes oficiais, saberes...

a escola, contribuiriam para acentuar a desigual distribuição dos bens simbólicos (BOURDIEU, 2007); porém, a atuação docente possibilita que a reprodução histórica da desigualdade venha a não se impor neste caso específico.

Por outro lado, o plano de trabalho também precisa responder ao poder público e às normas que legitimam o ingresso e a permanência do professor na Sala de Leitura. Essa resposta se realiza com base na perspectiva interdisciplinar que se propõe para a Sala de Leitura, conforme prevê o artigo $6^{\circ}$, da Portaria n. ${ }^{\circ} 7655 / 2015$ : "IV - articular, em conjunto com o POIE, do planejamento e desenvolvimento do trabalho na área de integração, envolvendo os demais professores da unidade", e, também, na proposta do Programa Mais Educação (SÃO PAULO [município], 2013, p. 85), de incluir no âmbito educacional questões relacionadas à violência, à prevenção e ao uso indevido de drogas. Assim, associando sua proposta às possibilidades previstas em outros programas de Educação da rede municipal de ensino, produz-se espaço de manobra (CERTEAU, 1994) para a proposição de atividades que não as estritamente vinculadas às diretrizes específicas para as Salas de Leitura.

O plano de trabalho em Sala de Leitura na EMEF C

O plano de trabalho "Do Livro à Mídia - Leitura e Releituras" foi proposto por POSL graduada em Letras e Pedagogia, em unidade escolar localizada nas proximidades das obras do trecho norte do Rodoanel (obra viária que circunda a região central da Grande São Paulo), escola mais segregada territorialmente, em comparação com as demais escolas observadas neste trabalho. $\mathrm{O}$ acesso a bens culturais e simbólicos, devido à inexistência de bibliotecas, cinemas, teatros ou outros espaços culturais, é extremamente limitado, limitação que se intensifica devido ao sistema deficitário de transporte público na região.

O plano de trabalho são propostas atividades de leituras e releituras de obras inicialmente publicadas em livros ou e-books e posteriormente adaptadas para o cinema. Os objetivos do plano de trabalho, a princípio, convergem para o estabelecido nas diretrizes institucionais para a Sala de Leitura:

fazer com que [os alunos] observem a qualidade do acervo de livros e dos títulos que serão lidos e comparados; ampliar o repertório de histórias que eles conhecem; criar espaços coletivos para o usufruto da leitura dentro da escola e fora da escola; enfocar a leitura como atividade diária na escola; desenvolver comportamentos leitores envolvidos nesta 
modalidade; estimulá-los a realizar com frequência e regularidade a leitura comparativa e crítica; analisar a qualidade dos textos e enredos; despertar o interesse pela leitura e observação das mídias produzidas a partir da literatura (SÃO PAULO [município], 2016c, p. 4).

Os três primeiros objetivos estão no escopo das diretrizes oficiais para as Salas de Leitura. Os objetivos seguintes se relacionam mais diretamente à proposta pedagógica que orienta o plano de trabalho em questão. Por conseguinte, diante desse contexto de adversidade, a presença do cinema no processo de aprendizagem da leitura parece responder à necessidade de ofertar mais acesso a bens culturais para os alunos, o que, via de regra, é prejudicado pela inexistência de equipamentos culturais no território.

Parece que a área de especialidade do POSL favorece um diálogo mais próximo de sua proposta de trabalho com as diretrizes oficiais estabelecidas para o desenvolvimento de atividades nas Salas de Leitura. Porém, mesmo nessa posição de maior proximidade com as injunções institucionais, o plano de trabalho excede os limites previstos oficialmente para a formação de leitores, ao associar a exposição a obras cinematográficas às atividades de leituras de textos literários. Esse vínculo é possibilitado, no plano de trabalho, pela interpretação ampliada do que se apresenta na própria normativa para as Salas de Leitura: "é preciso situar a função do POSL na unidade escolar como sendo o profissional responsável pelo trabalho com a leitura de múltiplos gêneros textuais que circulam na vida social" (SÃO PAULO [município], 2012, p. 15). Nesse caso, os "múltiplos gêneros textuais” são lidos de modo a reunir não apenas os gêneros literários, mas aqueles que também possam se materializar em outras modalidades, o que possibilita incluir as obras cinematográficas no plano de ensino proposto.

\section{Discussão}

A análise dos dados evidenciou que as professoras das Salas de Leitura produzem possibilidades de formação leitora não previstas pelas diretrizes oficiais, de modo a serem contempladas as especificidades dos saberes docentes em suas áreas de especialidade, e as especificidades dos contextos de atuação, com os sujeitos que deles participam.

Desse modo, as representações de leitura e de leitor que se constituem nos planos de trabalho analisados dialogam de modo complexo com as determinações institucionais, em razão das características próprias aos contextos sociais, econômicos 
A formação de leitores em Salas de Leitura: diretrizes oficiais, saberes...

e culturais em que se localizam as escolas e das bases epistemológicas em que se fundamenta a formação acadêmica dos professores proponentes.

Embora no material de apoio ao docente e nas diretrizes oficiais se considere que o ensino da literatura seja o objeto principal a ser ensinado nas Salas de Leitura, nos planos de trabalho analisados, as representações de leitura não parecem convergir para a perspectiva do prazer, da imaginação, do deleite, da fantasia, da emancipação individual, ou da leitura como um ato redentor em si mesmo, e igual para todos os grupos sociais, para quaisquer comunidades de leitores. Observa-se assim que os sujeitos, ao construírem as representações sociais sobre leitura, leitor e ensino da leitura, em tempos e espaços determinados, lidam com possibilidades de ajustes, de combinações (CHARTIER, 2010), dado que, se as regras institucionais não podem ser transgredidas, também não conseguem êxito pleno nas ações de controle que preveem.

No processo de construção de representações estudado, parece que a área específica de formação do professor condiciona a maior ou menor proximidade com as diretrizes institucionais para o funcionamento das Salas de Leitura, uma vez que as influências do contexto social, as relações de poder institucionalizadas e a construção de identidade dos sujeitos interferem diretamente no que se ensina e na forma como se ensina. Ou seja, as representações não se constroem aleatoriamente, mas condicionam e são condicionadas pelos modos como as pessoas organizam a realidade em suas mentes, como se definem os comportamentos e as práticas sociais (CHARTIER, 1990, p. 17).

Assim, e mesmo no plano de trabalho que mais de perto responde às diretrizes oficiais de formação para as Salas de Leitura (EMEF C), as propostas de ensino buscam responder às questões sociais, econômicas e culturais que se fazem prementes nos territórios em que se localizam as escolas. Com efeito, as representações de leitura precisam ser compreendidas, observando-se as relações estabelecidas entre fatores diversos: o contexto social, econômico, político e cultural; a posição dos sujeitos em uma determinada instituição e suas respostas à legislação e às diretrizes pedagógicas oficiais; o vínculo docente com sua formação acadêmica específica.

\section{CONSIDERAÇões Finais}

Os resultados da pesquisa possibilitam evidenciar que a formação do leitor nas Salas de Leitura se caracteriza, antes que pela determinação de representações oficiais de leitura a serem adotadas em contexto escolar, pela complexidade e pela heterogeneidade, tendo em vista a diversidade de características dos territórios, dos saberes 
docentes próprios aos professores que atuam nesses espaços educativos e das condições econômicas e culturais dos diferentes grupos sociais que compõem a escola.

A observação dessas características e dessas condições mostra-se ainda mais relevante quando se consideram os modos de constituição das representações de ensino de leitura e de leitor em territórios mais carentes social e economicamente, nos quais a escola - muitas vezes o único equipamento cultural nesses contextos - é a agência em que se podem oferecer oportunidades educativas e enfrentar as desigualdades na distribuição dos bens simbólicos e econômicos.

\section{REFERÊNCIAS}

BOURDIEU, P. A economia das trocas simbólicas. São Paulo: Perspectiva, 2007.

CARMO, E. S. R. Herdando uma biblioteca: uma investigação sobre espaços de leitura em uma escola da rede pública estadual. Dissertação (Mestrado em Língua e Cultura) - Faculdade de Educação, Universidade Federal da Bahia, Salvador, 2012.

CASTROGIOVANNI, A. C. Revisitando a alfabetização para trabalhar a geografia no ensino fundamental. In: SHÄFFER, N. O. (Org.). Ensinar e aprender Geografia. Porto Alegre: Associação dos Geógrafos Brasileiros - Seção Porto Alegre, 1998.

CASTROGIOVANNI, A. C. (Org.). Ensino de Geografia: práticas e textualizações no cotidiano. Porto Alegre: Mediação, 2000.

CASTROGIOVANNI, A. C.; COSTELLA, R. Z. Brincar e cartografar com os diferentes mundos geográficos: a alfabetização espacial. Porto Alegre: EDIPUCRS, 2006.

CERTEAU, M. A invenção do cotidiano. Rio de Janeiro: Vozes, 1994.

CHARTIER, R. História cultural - entre práticas e representações. Rio de Janeiro: Bertrand, 1990.

CHARTIER, R. O mundo como representação. Estudos Avançados, São Paulo/SP, v. 05, n. 11, jan./abr. 1991. Disponível em: http://www.scielo.br/pdf/ea/vsnı1/vsn11a1o.pdf. Acesso em: 12 dez. 2015.

CHARTIER, R. A aventura do livro: do leitor ao navegador. São Paulo: UNESP, 1999.

CHARTIER, R. Formas e sentido da cultura escrita: entre distinção e apropriação. Campinas: ALB; Mercado de Letras, 2003.

CHARTIER, A. M. Práticas de leitura e escrita. Belo Horizonte: Autêntica, 2007.

CHARTIER, R. A história ou a leitura do tempo. Belo Horizonte: Autêntica, 2010.

FIRMINO, E. M. A. Sala de Leitura na Rede Municipal de São Paulo: reflexões sobre eventos e práticas de letramento com uma turma de $4^{\circ}$ ano. Dissertação (Mestrado em Educação) - Faculdade de Educação, Universidade Federal de São Paulo (UNIFESP), São Paulo, 2015.

FOUCAULT, M. A ordem do discurso. São Paulo: Loyola, 1996.

FOUCAULT, M. A arqueologia do saber. Rio de Janeiro: Forense Universitária, 2013.

LEITE, A. C. S. M. O lugar da Sala de Leitura na Rede Municipal de Ensino de São Paulo. Dissertação (Mestrado em Educação) - Faculdade de Educação, Pontifícia Universidade Católica de São Paulo (PUC), São Paulo, 2009. 
A formação de leitores em Salas de Leitura: diretrizes oficiais, saberes...

MENDES, M. F. V. Sala de Leitura nas escolas da Rede Municipal de Ensino de São Paulo: uma inovação que resiste às descontinuidades políticas. Tese (Programa de Estudos Pós-Graduados em Educação, História, Política e Sociedade) - Faculdade de Educação, Pontifícia Universidade Católica - PUC, São Paulo, 2006.

PIOVESAN, L. R. Sala de leitura: atos, atores e ações. Dissertação (Mestrado em Ciências da Comunicação) - Escola de Comunicações e Artes, Universidade de São Paulo, São Paulo, 1999.

POLIDO, N. E. S. Salas de leitura na rede municipal de ensino do Estado de São Paulo: caminhos possíveis para redimensionar seu funcionamento. Tese (Doutorado em Educação) - Faculdade de Educação, Universidade de São Paulo, São Paulo, 2012.

SÃO PAULO (município). Secretaria Municipal de Educação. Leitura ao Pé da Letra - Caderno Orientador para Ambientes de Leitura. São Paulo: SME/DOT, 2012.v. 1-2. Disponível em: http:// portalsme.prefeitura.sp.gov.br. Acesso em: 20 out. 2015.

SÃO PAULO (município). Secretaria Municipal de Educação. Decreto n. 54.452, de 10/10/2013. Institui na SME-SP, o Programa de Reorganização Curricular e Administrativa, Ampliação e Fortalecimento da Rede Municipal de Ensino - Mais Educação São Paulo. Disponível em: https://goo.gl/xirVCI. Acesso em: 04 mar. 2016.

SÃO PAULO (município). Secretaria Municipal de Educação. Portaria n. 7.655, de 17/12/2015. Dispõe sobre a organização das Salas de Leitura, Espaços de Leitura e Núcleos de Leitura na Rede Municipal de Ensino. Disponível em: https://goo.gl/HvsfnM. Acesso em: 04 maio 2017. SÃO PAULO (município). Secretaria Municipal de Educação. Sala de Leitura. Projeto Alfabetização Cartográfica. São Paulo: SME, 2016a.

SÃO PAULO (município). Secretaria Municipal de Educação. Sala de Leitura. Projeto Drogas e Sexualidade. São Paulo: SME, 2016b.

SÃO PAULO (município). Secretaria Municipal de Educação. Sala de Leitura. Projeto Leituras e Releituras - Do livro à mídia. São Paulo: SME, 2016c.

TARDIF, M. Saberes docentes e formação profissional. Petrópolis: Vozes, 2004.

\section{SOBRE OS AUTORES}

Emerson de Pietri é graduado em Letras (Universidade Estadual de Campinas), tem Mestrado em Linguística Aplicada (Universidade Estadual de Campinas) e Doutorado em Linguística Aplicada (Universidade Estadual de Campinas). É professor/pesquisador da Faculdade de Educação da Universidade de São Paulo. Tem experiência na área de ensino de língua portuguesa, com pesquisa nos seguintes temas: formação de professores; história do ensino de língua portuguesa; ensino de leitura e de escrita.

E-mail: pietri@usp.br. 
Luciene de Cassia de Santana é graduada em Letras (Universidade de São Paulo). Tem Especialização em Alfabetização e Letramento (Centro Universitário Assunção - UNIFAI) e Mestrado em Linguagem, Educação e Psicologia (Universidade de São Paulo). Trabalha atualmente na Secretaria de Estado de Educação de São Paulo - SEDUC-SP. Tem experiência na área de formação de professores, com pesquisa nos seguintes temas: implementação e monitoramento de projetos na rede pública estadual; políticas públicas e diretrizes curriculares. E-mail: santanaluciene@hotmail.com.

Recebido em 15 de abril de 2018 e aprovado em 16 de julho de 2020. 